\title{
Prevalence of peripheral arterial occlusive disease in patients referred to a tertiary care hospital in Salvador, Bahia, Brazil, for coronary angiography
}

\author{
J.L.B. Nunes ${ }^{1}$, A. Silvany-Neto ${ }^{2}$, G.B.B. Pitta ${ }^{3}$, L.F.P. Figueiredo ${ }^{4}$, I. Oliveira ${ }^{6}$, \\ R. Quadros ${ }^{7}$ and F. Miranda-Junior ${ }^{5}$ \\ ${ }^{1}$ Serviço de Cirurgia Vascular, Hospital Agenor Paiva, Salvador, BA, Brasil \\ ${ }^{2}$ Departamento de Medicina Preventiva, Faculdade de Medicina, Universidade Federal da Bahia, \\ Salvador, BA, Brasil \\ ${ }^{3}$ Disciplina de Cirurgia Vascular, Departamento de Cirurgia, Universidade Estadual de Ciências da \\ Saúde de Alagoas, Maceió, AL, Brasil \\ ${ }^{4}$ Disciplina de Técnica Operatória e Cirurgia Experimental, ${ }^{5}$ Disciplina de Cirurgia Vascular, \\ Departamento de Cirurgia, Escola Paulista de Medicina, Universidade Federal de São Paulo, \\ São Paulo, SP, Brasil \\ ${ }^{6}$ Departamento de Acessos para Hemodiálise, Serviço de Cirurgia Vascular, Hospital Ana Nery, \\ Salvador, BA, Brasil \\ 7Escola Baiana de Medicina e Saúde Pública, Salvador, BA, Brasil
}

Correspondence to: J.L.B. Nunes, Av. Paulo VI, Qd-A, Rua B, 34, Pituba, 41810-001 Salvador, BA, Brasil E-mail: jafascionunes@terra.com.br

\begin{abstract}
The presence of peripheral arterial occlusive disease increases the morbidity and mortality of patients with coronary artery disease. The objective of the present study was to calculate the prevalence of peripheral arterial occlusive disease in patients referred for coronary angiography. This prevalence study was carried out at the Hemodynamics Unit of Hospital Santa Isabel, Salvador, Brazil, from December 2004 to April 2005. After approval by the Ethics Committee of the hospital, 397 patients with angiographic signs of coronary artery disease were enrolled. Diagnosis of peripheral arterial occlusive disease was made using the ankle-brachial blood pressure index $(\leq 0.90)$. Statistical analyses were performed using the $z$ test and a level of significance of $\alpha=5 \%, 95 \% \mathrm{Cl}$, the chi-square test and $t$-test, and multiple logistic regression analysis. The prevalence of peripheral arterial occlusive disease was $34.3 \%$ (95\% Cl: 29.4-38.9). Mean age was $65.7 \pm 9.4$ years for patients with peripheral arterial occlusive disease, and $60.3 \pm 9.8$ years for patients without peripheral arterial occlusive disease $(P=0.0000003)$. The prevalence of peripheral arterial occlusive disease was 1.57 times greater in patients with hypertension $(P=0.007)$ and 2.91 times greater in patients with coronary stenosis $\geq 50 \%$ ( $P=0.002$ ). Illiterate patients and those with little education had a $44 \%$ higher chance of presenting peripheral arterial occlusive disease probably as a result of public health prevention policies of limited effectiveness. The prevalence of peripheral arterial occlusive disease in patients referred to a tertiary care hospital in Salvador, Bahia, for coronary angiography, was $34.3 \%$.
\end{abstract}

Key words: Peripheral vascular diseases; Coronary atherosclerosis; Prevalence; Epidemiology; Ultrasound; Coronary angiography

Publication supported by FAPESP.

Received July 6, 2007. Accepted January 3, 2008 


\section{Introduction}

Peripheral arterial occlusive disease (PAOD) in patients with coronary artery disease (CAD) compromises the recovery and postoperative quality of life of patients who undergo myocardial revascularization $(1,2)$.

Early identification of PAOD by vascular surgeons in patients with CAD is fundamental to reduce morbidity and mortality in this group of patients (1,3-7).

Studies involving patients with CAD and PAOD have detected greater morbidity and mortality than among patients with only CAD. Patients with CAD and PAOD had a greater risk of cerebral vascular accidents after myocardial revascularization and a $25 \%$ increase in mortality $(4,6,8,9)$.

Although several investigators have reported the effects of PAOD on the survival of patients with CAD, few studies in the literature have estimated the prevalence of PAOD in patients with CAD using the ankle-brachial blood pressure index (ABPI) (10). The ethnic diversity and miscegenation of the Brazilian population require that epidemiological studies use high-quality diagnostic methods and include representative samples of the population to define the rate of high-risk patients and to promote early follow-up by vascular surgeons to prevent complications.

The objective of the present study was to estimate the prevalence of PAOD in patients referred for coronary angiography and presenting CAD. The prevalence of PAOD was also evaluated according to the severity of CAD, and the clinical, epidemiological and demographic characteristics of the sample were described.

\section{Material and Methods}

This prevalence study was conducted at the Hemodynamics Unit of Hospital Santa Izabel, Salvador, BA, Brazil. After approval by the Ethics Committee of the hospital, patients consecutively seen in this unit were enrolled from December 2004 to April 2005 during the three weekly material collection shifts. Patients were referred for angiography by the assistant physician based on clinical criteria, effort test or myocardial scintigraphy results. The authors of the study did not participate in angiography. The sample was selected sequentially at the Hemodynamics Unit. All patients included in the study signed an informed consent form.

A vascular surgeon on the study team conducted physical vascular examinations before coronary angiography during routine medical examination at the Hemodynamics Unit. PAOD was diagnosed by measurement of ABPI using a Medmega DV610 unit (Medmega Indústria de Equipamentos Médicos Ltda., Franca, SP, Brazil) for Dop- pler sonography. Patients were examined while lying down in a room at $25^{\circ} \mathrm{C}$ after resting for $30 \mathrm{~min}$. Systolic blood pressure was measured with a mercury sphygmomanometer placed at the level of the patient; the cuff was inflated to $10 \mathrm{mmHg}$ above the patient's systolic pressure and deflated at $2 \mathrm{mmHg} / \mathrm{s}$. Systolic pressure was measured in both arms and in the dorsal arteries of the foot and posterior tibial arteries of each lower extremity. To determine $\mathrm{ABPI}$, the greatest pressures found in the dorsal artery of the foot or posterior tibial artery of the right and left lower extremities were divided by the greatest pressure found for the right or left arm $(11,12)$. When this index was lower than or equal to 0.90 , the patient was diagnosed as having PAOD $(13,14)$. The values obtained by the two examiners for the first 30 measurements had good reproducibility, with a general agreement coefficient of $96 \%$ and kappa of 0.78 (15).

After coronary angiography was performed, only the patients with a diagnosis of CAD provided by the Hemodynamics Unit were included in the study. Severity of CAD was established by the hemodynamics specialist of the Unit. Stenosis that affected less than $50 \%$ of the coronary artery lumen was classified as wall abnormalities, and stenosis that affected $50 \%$ or more of the lumen was classified as one-, two- or three-vessel disease according to the number of coronary arteries compromised (16). Patients without atherosclerotic coronary artery alterations were excluded from the study.

Sample size was calculated to obtain the minimum number of individuals necessary to estimate prevalence (17), assuming a PAOD prevalence of $30 \%$, a $95 \%$ confidence level, precision of $5 \%$, and a design effect of 1.1 , and the result was a sample size of about 387 patients.

The $z$ test was used for statistical analysis at a $95 \%$ confidence interval $(95 \% \mathrm{Cl})$ and a level of significance of $\alpha$ $=5 \%$. The chi-square test was used to analyze the independence between variables, and the $t$-test to compare means. Multiple logistic regression analysis was used in multivariate analysis (18). Patients were described according to usual descriptive statistics $(17,19)$.

Hypertension, dyslipidemia, smoking, and diabetes mellitus were defined as clinical and epidemiological variables and classified as follows: hypertension: mild - controlled with 1 drug; moderate - controlled with 2 drugs; severe - controlled with $\geq 3$ drugs or not controlled; diabetes mellitus: mild - type II, controlled with diet or an oral hypoglycemic agent; moderate - type II controlled with insulin; severe - type I, juvenile diabetes; smoking: mild smoked in the last 10 years; moderate - smoked $<1$ pack/ day or quit $<1$ year before; severe - smoked $\geq 1$ pack/day; dyslipidemia: mild - easily controlled with diet; moderate - 
controlled with a strict diet; severe - controlled with diet and medication (20). Origin, sex, education, occupation, and marital status were defined as demographic variables. Education was classified as illiterate, primary (up to 4 years of primary education), secondary (up to third year of secondary education) or tertiary (higher education with or without graduate degrees).

\section{Results}

A total of 397 patients were examined. Mean age was $62 \pm 10$ years (range: 43 to 87 years). The prevalence of $\mathrm{PAOD}$ in patients referred for coronary angiography and presenting CAD was 34.3\% (136/397; 95\% Cl: 29.4-38.9). Mean age was $65.8 \pm 9.4$ years for patients with PAOD and $60.3 \pm 10$ years for patients without PAOD. The difference between mean ages was statistically significant $(P=$ 0.0000002 ; $t$-test).

Table 1 shows the demographic characteristics of the sample: $54.9 \%(218 / 397)$ of the patients were from Salvador, the state capital city; $59.4 \%$ (236/397) were illiterate or had primary education; $63.2 \%$ (251/397) were not retired, and $69.8 \%(277 / 397)$ were married. Of the patients with PAOD, $72.1 \%$ (98/136) were illiterate or had primary education, and $54.4 \%$ (74/136) were not retired.

The clinical and epidemiological characteristics of the sample are shown in Table 2: 34.3\% (136/397) had smoked in the past 10 years; $26.2 \%$ (104/397) had diabetes; $70.0 \%$ (278/397) had hypertension, and 60.3\% (239/397) had dyslipidemia. Of the patients with PAOD, $14.7 \%$ were heavy smokers and $40.4 \%$ had severe dyslipidemia.

The analysis of the association of clinical and epidemiological variables with PAOD showed that patients with hypertension had a statistically greater prevalence of the disease than patients without hypertension. The prevalence ratio for this association was $1.57(95 \% \mathrm{Cl}$ : 1.11 $2.24 ; \mathrm{P}=0.007$; chi-square test), which indicates that the prevalence of PAOD was 1.57 times greater in patients with hypertension. The associations with the other variables were not statistically significant (Table 3 ).

Table 4 shows the frequency of each type of coronary lesion. Of the 397 patients in the sample, 88.2\% (350) had $\geq 50 \%$ stenosis in at least one coronary artery, and $40.2 \%$ of patients with PAOD had two-vessel disease.

Table 5 shows the separate comparisons between each type of coronary lesion and other lesions. Patients with one-, two- or three-vessel disease had a statistically greater prevalence of PAOD than patients with wall abnormalities. Similarly, when patients with one-, two- or threevessel disease were compared as a single group, their prevalence of PAOD was statistically greater than among
Table 1. Distribution of demographic variables in the overall sample and in patients with peripheral arterial occlusive disease (PAOD).

\begin{tabular}{lcc}
\hline Variable & Overall sample & With PAOD \\
\hline Sex & & \\
$\quad$ Male & $249(62.7 \%)$ & $77(56.6 \%)$ \\
Female & $148(37.3 \%)$ & $59(43.4 \%)$ \\
Origin & & \\
$\quad$ Capital city & $218(54.9 \%)$ & $77(56.6 \%)$ \\
Other cities & $179(45.1 \%)$ & $59(43.4 \%)$ \\
Education & & \\
$\quad$ Illiterate & $37(9.3 \%)$ & $16(11.8 \%)$ \\
Primary & $199(50.1 \%)$ & $82(60.3 \%)$ \\
Secondary & $110(27.7 \%)$ & $27(19.8 \%)$ \\
$\quad$ Tertiary & $51(12.9 \%)$ & $11(8.0 \%)$ \\
Occupation & & \\
$\quad$ Not retired & $251(63.2 \%)$ & $74(54.4 \%)$ \\
Retired & $146(36.8 \%)$ & $62(45.6 \%)$ \\
Marital status & & \\
$\quad$ Married & $277(69.8 \%)$ & $91(66.9 \%)$ \\
Widowed & $58(14.6 \%)$ & $26(19.1 \%)$ \\
Single & $44(11.1 \%)$ & $13(9.6 \%)$ \\
Separated/divorced & $18(4.5 \%)$ & $6(4.4 \%)$ \\
\hline
\end{tabular}

Data are reported as number with percent in parentheses.

Table 2. Distribution of clinical and epidemiologic variables in the overall sample and in patients with peripheral arterial occlusive disease (PAOD).

\begin{tabular}{lcc}
\hline Variable & Overall sample & With PAOD \\
\hline Smoking & & \\
$\quad$ Severe & $46(11.6 \%)$ & $20(14.7 \%)$ \\
Moderate & $28(7.1 \%)$ & $9(6.6 \%)$ \\
Mild & $62(15.6 \%)$ & $20(14.7 \%)$ \\
No smoking & $261(65.7 \%)$ & $87(64.0 \%)$ \\
Diabetes mellitus & & \\
Severe & $0(0 \%)$ & $0(0 \%)$ \\
Moderate & $23(5.8 \%)$ & $12(8.8 \%)$ \\
Mild & $81(20.4 \%)$ & $29(21.3 \%)$ \\
$\quad$ No diabetes & $293(73.8 \%)$ & $95(69.9 \%)$ \\
Hypertension & & \\
Severe & $56(14.1 \%)$ & $15(11.1 \%)$ \\
Moderate & $104(26.2 \%)$ & $49(36.0 \%)$ \\
Mild & $118(29.7 \%)$ & $43(31.6 \%)$ \\
No hypertension & $119(30.0 \%)$ & $29(21.3 \%)$ \\
Dyslipidemia & & \\
$\quad$ Severe & $152(38.3 \%)$ & $55(40.4 \%)$ \\
Moderate & $30(7.6 \%)$ & $8(5.9 \%)$ \\
Mild & $57(14.4 \%)$ & $25(18.4 \%)$ \\
No dyslipidemia & $158(39.8 \%)$ & $48(35.3 \%)$ \\
& &
\end{tabular}

Data are reported as number with percent in parentheses. 
Table 3. Association of clinical and epidemiologic variables with peripheral arterial occlusive disease (PAOD) in 397 patients.

\begin{tabular}{|c|c|c|c|c|}
\hline \multirow[t]{2}{*}{ Variable } & \multicolumn{2}{|c|}{ PAOD } & \multirow{2}{*}{$\begin{array}{l}\text { Prevalence } \\
\text { ratio }\end{array}$} & \multirow{2}{*}{$95 \% \mathrm{Cl}$} \\
\hline & Yes & No & & \\
\hline \multicolumn{5}{|l|}{ Smoking } \\
\hline Yes & 49 (36.0\%) & 87 (64.0\%) & 1.08 & $0.82-1.43$ \\
\hline No & $87(33.3 \%)$ & $174(66.7 \%)$ & & \\
\hline \multicolumn{5}{|c|}{ Diabetes mellitus } \\
\hline Yes & 41 (39.4\%) & $63(60.6 \%)$ & 1.22 & $0.91-1.62$ \\
\hline No & 95 (32.4\%) & $198(67.6 \%)$ & & \\
\hline \multicolumn{5}{|c|}{ Hypertension } \\
\hline Yes & 107 (38.5\%) & 171 (61.5\%) & 1.57 & $1.11-2.24$ \\
\hline No & $29(24.4 \%)$ & $90(75.6 \%)$ & & \\
\hline \multicolumn{5}{|c|}{ Dyslipidemia } \\
\hline Yes & $88(36.8 \%)$ & $151(63.2 \%)$ & 1.21 & $0.91-1.62$ \\
\hline No & $48(30.4 \%)$ & $110(69.6 \%)$ & & \\
\hline
\end{tabular}

Data are reported as number with percent in parentheses, prevalence ratio or $95 \% \mathrm{Cl}$ (95\% confidence interval).

*Statistically significant (Taylor series method).

Table 4. Severity of coronary artery disease (CAD) in the overall sample and in patients with peripheral arterial occlusive disease (PAOD).

\begin{tabular}{lcr}
\hline Severity & Overall sample & With PAOD \\
\hline Three-vessel CAD & $139(35.0 \%)$ & $52(37.4 \%)$ \\
Two-vessel CAD & $102(25.7 \%)$ & $41(40.2 \%)$ \\
One-vessel CAD & $109(27.5 \%)$ & $37(33.9 \%)$ \\
Wall abnormalities & $47(11.8 \%)$ & $6(12.8 \%)$ \\
\hline
\end{tabular}

Data are reported as number with percent in parentheses.

Table 5. Association between severity of coronary artery disease and peripheral arterial occlusive disease.

\begin{tabular}{lcccc}
\hline Comparisons & PR & $95 \% \mathrm{Cl}$ & $\chi^{2}$ & $\mathrm{P}$ \\
\hline 3V x WA & 2.93 & $1.35-6.38$ & 8.83 & $0.003^{*}$ \\
3V x 1V & 1.10 & $0.79-1.55$ & 0.19 & 0.666 \\
3V x 2V & 0.93 & $0.68-1.28$ & 0.09 & 0.760 \\
2V x WA & 3.15 & $1.40-6.90$ & 9.98 & $0.002^{*}$ \\
2V x 1V & 1.18 & $0.83-1.69$ & 0.64 & 0.425 \\
1V x WA & 2.66 & $1.20-5.78$ & 6.35 & $0.012^{*}$ \\
3V, 2V, and 1V x WA & 2.91 & $1.36-6.22$ & 9.88 & $0.002^{*}$ \\
\hline
\end{tabular}

$1 \mathrm{~V}=$ one-vessel disease; $2 \mathrm{~V}=$ two-vessel disease; $3 \mathrm{~V}=$ threevessel disease; $\mathrm{WA}=$ wall abnormalities; $\mathrm{PR}=$ prevalence ratio; $95 \% \mathrm{Cl}=95 \%$ confidence interval; $\chi^{2}=$ chi-square test. ${ }^{*} \mathrm{P}<0.05$ (Taylor series method and chi-square test). patients with wall abnormalities.

Mean ABPI was $0.94 \pm 0.21$. Mean ABPI for patients with diabetes was $0.93 \pm 0.22$, but the difference was not statistically significant when compared with the mean value of $0.94 \pm 0.19$ for patients without diabetes.

Table 6 presents the results of multivariate analysis. The clinical/epidemiological and social/demographic variables considered in the study were as follows: angiography result (one-, two-, or three-vessel disease versus parietal irregularities), interaction term between hypertension and angiography result, education (illiterate and little schooling versus others), age (years), interaction term between age and dyslipidemia, dyslipidemia (yes versus no), and hypertension (yes versus no). This analysis obtained an adequate power $(97 \%)$ to investigate the variable education level only. Illiterate patients and those with little education showed a $44 \%$ higher chance of presenting PAOD.

Patients also underwent a physical vascular examination. Results showed that $4.5 \%$ (18/397) had carotid bruit, $1.7 \%(7 / 397)$ had decreased pulse and blood pressure in the upper extremities, and $43.8 \%$ (174/397) had reduced or no pulse in at least one of the posterior tibial arteries or dorsal arteries of the foot in the lower extremities. No abnormalities were found in thorax or abdomen.

\section{Discussion}

The prevalence of PAOD in patients with CAD ranges from 5 to $40 \%(5,10,21-26)$. Such broad range may be justified by the fact that prevalence studies enroll different populations, are not randomized, investigate few clinical presentations of coronary disease, and use different diagnostic methods. Most studies that used ABPI enrolled small samples, sometimes only hospitalized patients who probably had more severe CAD. Therefore, comparisons with results of studies that selected large and diversified samples of patients with CAD are difficult $(10,19)$.

The measurement of ABPI is a widely accepted method for epidemiological studies $(13,14)$. However, results vary according to the time when patients are examined and who performs the measurements (27). This index also shows a greater number of false-negative results among patients with diabetes because of the calcification of artery walls. It is estimated that 5 to $10 \%$ of patients with diabetes have an artificial elevation of blood pressure due to the incompressibility of vessels, and that blood pressure differences between patients with and without diabetes is about $25 \mathrm{mmHg}$ (28). One alternative to reduce the number of false-negative results is to use toe blood pressure measurements $(13,14)$, but this method is not widely ac- 
cepted because of its low sensitivity (29). False-negative results in patients with diabetes may not have significantly affected the results of the present study because the difference in mean ABPI between patients with and without diabetes was not statistically significant. Studies that use color Doppler sonography to investigate PAOD in patients with CAD are not easily compared with our study because their measurement criteria are the visualization of an atherosclerotic plaque and the measurement of stenosis (1,3,30-33). The ABPI has been shown to correlate with clinical involvement and hemodynamic repercussions of stenosis in the peripheral artery system of the lower extremities (34).

In our study, PAOD was more prevalent among patients with two-vessel disease and was associated with $\geq 50 \%$ stenosis. Other studies also found a higher frequency of PAOD in patients with more severe CAD (21.3 to $25 \%$ ), but did not evaluate the statistical significance of their results $(5,10)$. This information provides scientific evidence to support early vascular screening of patients with CAD who are at a greater risk of having PAOD.

The description of the demographic characteristics of patients in this prevalence study is important because little education and a low socioeconomic status have been described as important risk factors for cardiovascular diseases $(35,36)$. Moreover, PAOD has been found to be associated with geographical location and population under study $(13,14)$. Most studies about the prevalence of PAOD in patients with CAD were conducted in developed countries, whose population profiles and public health policies reflect their socioeconomic reality. The description of demographic characteristics of patients with PAOD in our study showed that most patients worked, had a family, and had little education. Therefore, the poor control of this disease and the lack of specialized followup of these patients may represent a high socioeconomic cost for developing countries $(37,38)$. Moreover, many patients in our study came from other cities in the State of Bahia, which may suggest little decentralization of the health system. The great patient demand that results from such centralization may impair the provision of adequate health care (37).

In the present study, the frequency of risk factors for atherosclerotic disease was high and similar to that found in other studies $(31,39,40)$. Possible explanations for the broad variation in the prevalence of these risk factors among different ethnic groups are economic and sociocultural factors, which may be responsible for the high frequency of cardiovascular disease in developing countries (35). The cardiovascular risk profile of the population was critical in the city where this study was conducted, which has more than $2,500,000$ inhabitants, $70 \%$ of whom have mixed ethnic backgrounds, and most have little education and a low income. Improvements in educational levels and socioeconomic status may decrease the high frequency of risk factors (39).

This study was designed to estimate the prevalence of PAOD in the lower extremities of patients referred for coronary angiography and presenting CAD, and, therefore, the results of the physical examination of other segments cannot be statistically interpreted. However, abnormalities found in the upper extremities and carotid arteries support the findings of studies that have emphasized the importance of broad diagnostic screening examinations in patients with atherosclerotic disease because of the possible simultaneous involvement of several organs (7).

To sum up, the prevalence of PAOD in patients referred for coronary angiography and presenting CAD in the present study was $34.3 \%$, and was associated with illiteracy or little education, older age, hypertension, and coronary stenosis $\geq 50 \%$. Such a high prevalence rate stresses the need for early and routine evaluation of patients with CAD by vascular surgeons to prevent the severe complications of associated PAOD.

Table 6. Association between prevalence of peripheral arterial occlusive disease and clinical/epidemiological and social/demographic variables: results of the logistic regression model.

\begin{tabular}{lccccr}
\hline Variable & $B$ & $\mathrm{SE}_{\beta}$ & $\mathrm{P}$ & Odds ratio & $95 \% \mathrm{Cl}$ \\
\hline $\begin{array}{l}\text { Coronary angiography result } \\
\text { Interaction term between hypertension and coronary }\end{array}$ & 0.61 & 0.24 & 0.005 & 1.83 & $1.32-2.54$ \\
$\quad$ angiography result & 0.39 & 0.24 & 0.112 & 1.47 & $1.06-2.04$ \\
$\quad$ Education & 0.37 & 0.12 & 0.002 & 1.44 & $1.22-1.70$ \\
Age & 0.05 & 0.01 & 0.000 & 1.05 & $1.03-1.07$ \\
Interaction term between age and dyslipidemia & 0.02 & 0.01 & 0.079 & 1.02 & $1.01-1.04$ \\
$\quad \begin{array}{l}\text { Dyslipidemia } \\
\text { Hypertension }\end{array}$ & -1.24 & 0.82 & 0.134 & 0.29 & $0.09-0.90$ \\
& -0.07 & 0.20 & 0.766 & 0.93 & $0.67-1.29$
\end{tabular}

$\mathrm{SE}_{\beta}=$ standard error of beta; $95 \% \mathrm{Cl}=95 \%$ confidence interval . 


\section{References}

1. Cirillo F, Renzulli A, Leonardo G, Crescenzi B, Romano G, Tesorio MG, et al. Prevalence of vascular disease in candidates for myocardial revascularization with aortocoronary bypass: review of the literature and practical implications. Ital Heart J Suppl 2001; 2: 287-293.

2. Nikolsky E, Mehran R, Dangas GD, Lasic Z, Mintz GS, Negoita M, et al. Prognostic significance of cerebrovascular and peripheral arterial disease in patients having percutaneous coronary interventions. Am J Cardiol 2004; 93: 15361539.

3. Ciccone M, di Noia D, di Michele L, Corriero F, Di Biase M, Biasco MG, et al. The incidence of asymptomatic extracoronary atherosclerosis in patients with coronary atherosclerosis. Int Angiol 1993; 12: 25-28.

4. Eagle KA, Rihal CS, Foster ED, Mickel MC, Gersh BJ. Long-term survival in patients with coronary artery disease: importance of peripheral vascular disease. The Coronary Artery Surgery Study (CASS) Investigators. J Am Coll Cardiol 1994; 23: 1091-1095.

5. Atmer B, Jogestrand T, Laska J, Lund F. Peripheral artery disease in patients with coronary artery disease. Int Angiol 1995; 14: 89-93.

6. Salasidis GC, Latter DA, Steinmetz OK, Blair JF, Graham AM. Carotid artery duplex scanning in preoperative assessment for coronary artery revascularization: the association between peripheral vascular disease, carotid artery stenosis, and stroke. J Vasc Surg 1995; 21: 154-160.

7. Cournot M, Cambou JP, Ferrieres J, Grenier O, Herrmann MA, Cantet $\mathrm{C}$, et al. Management of the cardiology patient with polyvascular disease: PRISMA study. Arch Mal Coeur Vaiss 2004; 97: 841-848.

8. Higgins TL, Estafanous FG, Loop FD, Beck GJ, Blum JM, Paranandi L. Stratification of morbidity and mortality outcome by preoperative risk factors in coronary artery bypass patients. A clinical severity score. JAMA 1992; 267: 23442348.

9. Rao V, Christakis GT, Weisel RD, Ivanov J, Peniston CM, Ikonomidis JS, et al. Risk factors for stroke following coronary bypass surgery. J Card Surg 1995; 10: 468-474.

10. Sim EK, Koo G, Adebo OA, Lim MC, Choo MH, Lee CN. Prevalence of peripheral artery disease in patients with coronary artery disease. Ann Acad Med Singapore 1993; 22: 898-900.

11. Hiatt WR, Hoag S, Hamman RF. Effect of diagnostic criteria on the prevalence of peripheral arterial disease. The San Luis Valley Diabetes Study. Circulation 1995; 91: 14721479.

12. Sacks D, Bakal CW, Beatty PT, Becker GJ, Cardella JF, Raabe RD, et al. Position statement on the use of the anklebrachial index in the evaluation of patients with peripheral vascular disease: a consensus statement developed by the Standards Division of the Society of Cardiovascular and Interventional Radiology. J Vasc Interv Radiol 2002; 13: 353.

13. Dormandy JA, Rutherford RB. Management of peripheral arterial disease (PAD). TASC Working Group. TransAtlantic Inter-Society Consensus (TASC). J Vasc Surg 2000; 31: S1-S296.

14. TASC II Working Group. Management of peripheral arterial disease. TransAtlantic Inter-Society Consensus. J Vasc Surg 2007; 45: S7A-S13A.

15. Pereira MG. Epidemiologia, teoria e prática. Rio de Janeiro: Guanabara Koogan; 1995.

16. James TN, Bruschke AV, Bothig S, Dodu SR, Gil JF, Kawamura K, et al. Report of WHO/ISFC Task Force on Nomenclature of Coronary Arteriograms. Circulation 1986; 74: 451A-455A.

17. Daniel WW. Biostatistics: A foundation for analysis in the health sciences. 7th edn. New York: John Wiley \& Sons; 1998.

18. Hosmer DW, Lemeshow S. Applied logistic regression. 2nd edn. New York: John Wiley \& Sons; 2000.

19. Fleiss JL. Statistical methods for rates proportions. 2nd edn. New York: John Wiley \& Sons; 1981.

20. Rutherford RB, Baker JD, Ernst C, Johnston KW, Porter $\mathrm{JM}$, Ahn S, et al. Recommended standards for reports dealing with lower extremity ischemia: revised version. $J$ Vasc Surg 1997; 26: 517-538.

21. Dieter RS, Tomasson J, Gudjonsson T, Brown RL, Vitcenda $M$, Einerson J, et al. Lower extremity peripheral arterial disease in hospitalized patients with coronary artery disease. Vasc Med 2003; 8: 233-236.

22. Aronow WS, Ahn C. Prevalence of coexistence of coronary artery disease, peripheral arterial disease, and atherothrombotic brain infarction in men and women $>$ or $=62$ years of age. Am J Cardiol 1994; 74: 64-65.

23. Hamby RI, Aintablian A, Shanies S, Wisoff BG, Weisz D, Voleti C. Angina pectoris and intermittent claudication. Am Heart J 1977; 94: 573-578.

24. McDonald L. Ischaemic heart disease and peripheral occlusive arterial disease. Br Heart J 1953; 15: 101-107.

25. Lamme S, Johansson BW, Lindell SE. Peripheral atherosclerosis in patients with myocardial infarction. Angiology 1984; 35: 373-379.

26. Huelmos A, Jimenez J, Guijarro C, Belinchon JC, Puras E, Sanchez $C$, et al. Underrecognized peripheral arterial disease in patients with acute coronary syndrome: prevalence of traditional and emergent cardiovascular risk factors. Rev Esp Cardiol 2005; 58: 1403-1410.

27. Baker JD, Dix DE. Variability of Doppler ankle pressures with arterial occlusive disease: an evaluation of ankle index and brachial-ankle pressure gradient. Surgery 1981; 89: 134-137.

28. Raines JK, Darling RC, Buth J, Brewster DC, Austen WG. Vascular laboratory criteria for the management of peripheral vascular disease of the lower extremities. Surgery 1976; 79: 21-29.

29. Kröger K, Stewen C, Santosa F, Rudofsky G. Avaliações da pressão arterial obtida em pododáctilos comparadas com avaliações obtidas em tornozelo. Angiology-Brasil 2004; 1 : 9-14.

30. Khoury Z, Schwartz R, Gottlieb S, Chenzbraun A, Stern S, Keren A. Relation of coronary artery disease to atherosclerotic disease in the aorta, carotid, and femoral arteries evaluated by ultrasound. Am J Cardiol 1997; 80: 1429-1433.

31. Crescenzi B, Cirillo F, Leonardo G, Porreca GP, De Angelis $M$, Di Benedetto $B$, et al. Vascular pathology of surgical significance in subjects with history of previous myocardial 
infarction. Minerva Cardioangiol 1998; 46: 308-309.

32. Hodara M, Bonithon-Kopp C, Courbon D, Guerin F, Richard J. Extra-coronary atherosclerosis in documented coronary patients. Arch Mal Coeur Vaiss 1998; 91: 201-207.

33. Cerne A, Kranjec I. Atherosclerotic burden in coronary and peripheral arteries in patients with first clinical manifestation of coronary artery disease. Heart Vessels 2002; 16: 217 226.

34. Yao JS. New techniques in objective arterial evaluation. Arch Surg 1973; 106: 600-604.

35. Yusuf S, Reddy S, Ounpuu S, Anand S. Global burden of cardiovascular diseases: Part II: variations in cardiovascular disease by specific ethnic groups and geographic regions and prevention strategies. Circulation 2001; 104: 2855-2864.

36. Hahn RA, Heath GW, Chang MH. Cardiovascular disease risk factors and preventive practices among adults - United States, 1994: a behavioral risk factor atlas. Behavioral Risk
Factor Surveillance System State Coordinators. MMWR CDC Surveill Summ 1998; 47: 35-69.

37. Nunes JLB, Araujo Filho JS, Silvany Neto AM, Andrade CS, Duque BC, Costa FPM, et al. Doença arterial periférica de membros inferiores em hospitais públicos de Salvador: perfil dos pacientes e do atendimento. J Vasc Bras 2002; 1: 201206.

38. Mello LV, Fonseca Filho VL, Essinger LA, Tibiriça A. O problema das emergências no Rio de Janeiro. Rev Angiol Cir Vasc 2005; 2: 94-96.

39. Lessa I, Araujo MJ, Magalhaes L, Almeida FN, Aquino E, Costa MC. Clustering of modifiable cardiovascular risk factors in adults living in Salvador (BA), Brazil. Rev Panam Salud Publica 2004; 16: 131-137.

40. Oliveira GM, Klein $\mathrm{CH}$, Souza e Silva NA. Mortality from cardiovascular diseases in three Brazilian states from 1980 through 2002. Rev Panam Salud Publica 2006; 19: 85-93. 